\title{
MODERNIZATION AND ACTIVATION OF THE NASA AMES 11-BY 11-FOOT TRANSONIC WIND TUNNEL
}

\author{
By \\ Frank J. Kmak \\ NASA Ames Research Center \\ Moffett Field, CA
}

\begin{abstract}
The Unitary Plan Wind Tunnel (UPWT) was modernized to improve performance, capability, productivity, and reliability. Automation systems were installed in all three UPWT tunnel legs and the Auxiliaries facility. Major improvements were made to the four control rooms, model support systems, main drive motors, and main drive speed control. Pressure vessel repairs and refurbishment to the electrical distribution system were also completed. Significant changes were made to improve test section flow quality in the 11By 11-Foot Transonic leg. After the completion of the construction phase of the project, acceptance and checkout testing was performed to demonstrate the capabilities of the modernized facility. A pneumatic test of the tunnel circuit was performed to verify the structural integrity of the pressure vessel before wind-on operations. Test section turbulence, flow angularity, and acoustic parameters were measured throughout the tunnel envelope to determine the effects of the tunnel flow quality improvements. The new control system processes were thoroughly checked during wind-off and wind-on operations. Manual subsystem modes and automated supervisory modes of tunnel operation were validated. The aerodynamic and structural performance of both the new composite compressor rotor blades and the old aluminum rotor blades was measured. The entire subsonic and supersonic envelope of the 11-By 11-Foot Transonic leg was defined up to the maximum total pressure.
\end{abstract}

\section{INTRODUCTION}

The Ames Unitary Plan Wind Tunnel facility has been the most heavily used wind tunnel in all of NASA. The UPWT was completed in 1956 at a cost of $\$ 27$ million under the Unitary Plan Act of 1949. Every major commercial transport and almost every military jet built in the United States over the last 45 years has been tested in this facility. Also tested in this tunnel complex were models of the Space Shuttle, as well as the Mercury, Gemini, and Apollo capsules.

The UPWT consists of three tunnel legs and an Auxiliaries facility: the 11-By 11-Foot Transonic leg, the 9-By 7-Foot Supersonic leg, and the 8-By 7-Foot Supersonic leg, Figure 1. The two supersonic legs share a common eleven-stage axial-flow compressor and aftercooler drive leg, and use diversion valves at the ends of the common leg. The 11-By 11-Foot leg is driven by a three-stage axial-flow compressor. A common drive motor system can be coupled to either the three-stage or eleven-stage compressors. One tunnel can therefore be run while the other two are in the process of installing or removing test articles.

The 11-By 11-Foot Transonic leg is a closed circuit, variable pressure, continuous operation wind tunnel, Figure 2. Subsonic Mach number control is accomplished by setting the compressor drive speed to one of ten setpoints and using variable camber Inlet Guide Vanes for fine Mach number control. Supersonic Mach number control involves setting the flexible wall nozzle to achieve the proper area ratio in addition to setting the compressor drive speed and the Inlet Guide Vanes. A tandem diffuser system with an annular diffuser followed by a wide-angle diffuser is upstream of a 70-foot diameter aftercooler section in the drive leg. The settling chamber upstream of the contraction is now 38 feet in diameter after the installation of a liner fairing that is 6 inches thick to accommodate flow conditioning element support hardware. The contraction provides a transition from the circular cross-section of the settling chamber to the square cross-section of the test section. The contraction ratio is 9.4. The test section is 11-by-11 feet in cross section and 22 


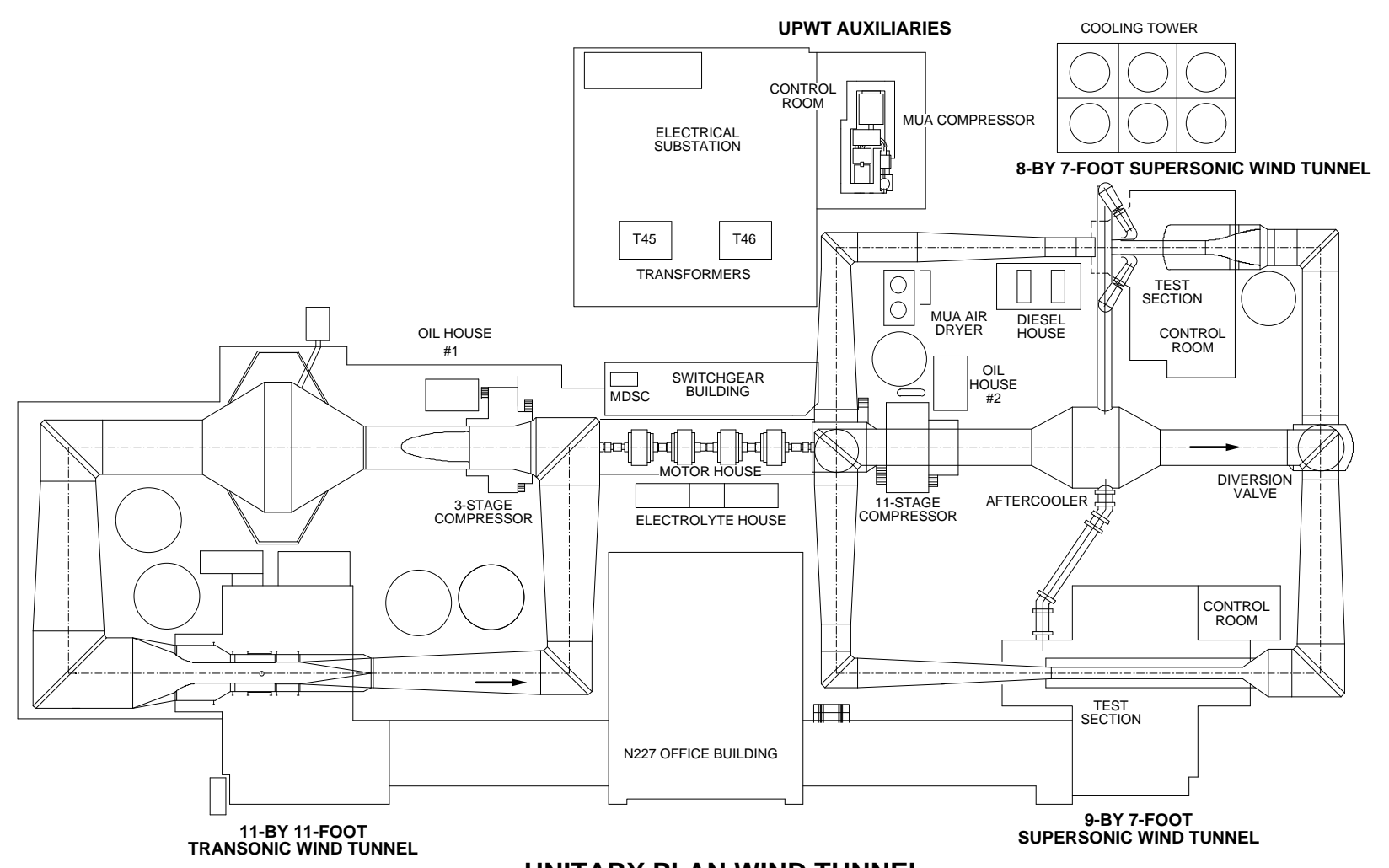

Figure 1. Unitary Plan Wind Tunnel Site Plan

feet in length. Slots in all four walls run the full length of the test section and include baffles that provide a porosity of $6 \%$ into the plenum. Ejector flaps on all four walls at the exit of the test section can be remotely set to control the plenum flow bypassed from the test section. Flow leaves the test section and enters a transition region back to the circular main diffuser. A Plenum Evacuation System (PES) provides an active method of removing air from the test section plenum using the Make-Up Air (MUA) compressor system in the Auxiliaries facility.

\section{UPWT MODERNIZATION}

Modernization and refurbishment studies were initiated in early 1988, and the UPWT Modernization Project (UMP) requirements were written in the summer of 1988. A second project, the Performance Improvement Project (PIP), was funded in 1994 and combined with the UMP for construction. The UPWT Modernization Project was initially funded for $\$ 60.4$ million, and with the addition of the PIP, the combined project was funded at approximately $\$ 80$ million. NASA Ames functioned as the general contractor and managed the integration of the twenty-one work packages.
The supersonic legs of the UPWT are not as heavily utilized as the transonic leg. They were removed from service before the 11-By 11-Foot leg and the Auxiliaries in order to complete their control room construction before the 11-By 11Foot construction. The 8-By 7-Foot Supersonic leg was taken out of service in October, 1993, and the control room rebuilt and completed in August, 1994. The 9-By 7-Foot Supersonic leg was taken out of service in October, 1994, and the control room rebuilt and completed in July, 1995. The 11By 11-Foot Transonic leg and the Auxiliaries facility control rooms were taken out of service in April, 1995 and completed in March, 1996. 


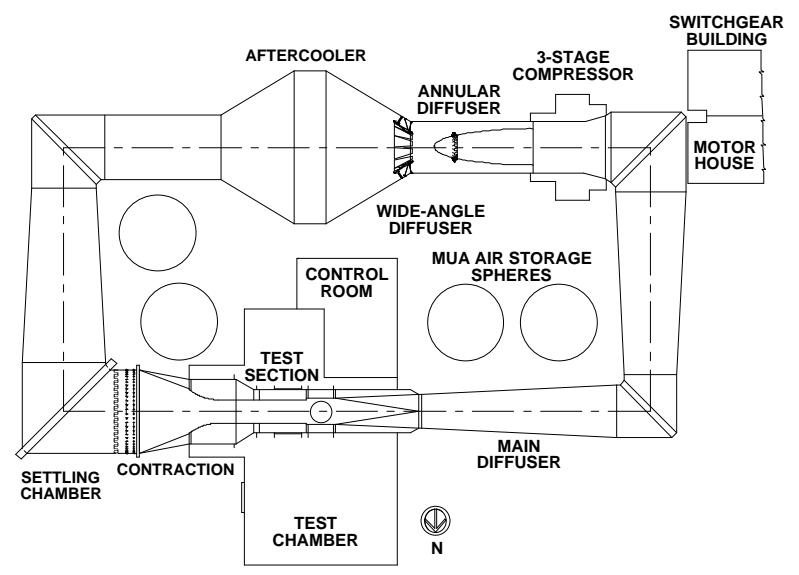

Figure 2. 11-By 11-Foot Transonic Wind Tunnel

\subsection{AUTOMATION SYSTEMS}

The primary objective of the Facility Control System (FCS) upgrade was to automate the three legs of the UPWT and the associated Auxiliaries support facility. Automation of the tunnel operation allows test operators to enter a series of test conditions and model angle schedules into run schedule tables prior to a run series. The processes of moving the model through a movepause or continuous sweep polar, taking data at each point, maintaining the tunnel total pressure, and maintaining the tunnel Mach number, have been fully automated. The operator interacts with the control system to monitor the processes and step the system to the next tunnel condition or model polar.

The Auxiliaries support facility houses the MakeUp Air (MUA) compressor, which supplies dry air for pressurization of the three tunnels. The Auxiliaries facility also includes a separate control room, vacuum pump system, cooling tower, electrical switchgear for the main drive motors, and lubrication systems for motors and compressors. The old control consoles used pistol grips, buttons, and gages to control and monitor the Auxiliaries and wind tunnel processes.

The automation effort included providing a Distributed Control System (DCS) in all four facilities with control software defined by Ames, replacement of existing facility instrumentation and control system wiring, and new control consoles in each control room. Over 3000 new sensors and actuators were deployed to modernize the four facilities. A completely new Hard-Wired Safety System (HWSS) has also been installed to mitigate facility hazards and to provide an independent layer of safety. This system consists of over 10,000 relays, switches, and other protective devices spread out over the four facilities. Nine new Motor Control Centers (MCC) were installed to replace obsolete motor switchgear. A new anti-surge control system was installed to protect the MUA compressor. A modern vibration monitoring system was installed to provide health monitoring of the 30 bearings associated with the MUA drive train and MUA compressors, as well as the four main drive motors and tunnel compressor drive shafts. The DCS, HWSS, and other component systems together comprise the FCS.

\subsection{MODERNIZED CONTROL ROOMS}

The scope of work for control room modernization included remodeling and enlarging the three tunnel control rooms and the Auxiliaries facility control room. The old control rooms contained the original facility control benchboards and were not large enough to accommodate both the operating staff and the customer staff. The new rooms feature a modern control console that houses the automation operating stations. Advanced indirect overhead lighting systems have been installed to reduce computer monitor glare. Structural upgrades to meet current seismic codes, computer access floors, an updated fire alarm and suppression system, extensive use of sound attenuation materials, a card key access system, and three separate power systems were provided in each control room. The power systems include building power, "clean" instrumentation power, and control system power. The facility control system is connected to an Uninterruptible Power Supply (UPS) system to allow the tunnel systems to shut down safely during a power outage. Each new tunnel control room has approximately two thousand square feet and accommodates data acquisition and control systems as well as facility and customer staff. A small instrumentation repair room is also included in each tunnel control room to facilitate on-site repair of model and data system electronics.

\subsection{TUNNEL FLOW QUALITY IMPROVEMENTS}

The objective of the flow quality improvements was to reduce the turbulence, flow angularity and low frequency Mach number fluctuations in the test section of the 11-By 11-Foot Transonic leg. The flexible wall nozzle in the 11-By 11-Foot leg was also replaced to increase dynamic stability 
during supersonic operations. The performance goal for the Turbulence Reduction System (TRS) was to reduce the test section turbulence level to less than $0.2 \%$ at a Mach number of 0.80 . The flow angularity goals were to reduce the mean angularity in the alpha and beta directions to less than 0.05 degrees and the root-mean-square deviation in both directions to less than 0.10 degrees in a core test section area. A TRS consisting of a honeycomb and two screens was installed in the settling chamber of the tunnel. The honeycomb is composed of one-inch hexagon cells twenty inches deep ( $25 \mathrm{~mm}$ by $500 \mathrm{~mm}$ ). The structure is fixed at the tunnel shell and is self-supporting. The factory-made honeycomb modules were installed in 8-by 10-foot pieces and then connected to each other by field spot welding using butterfly connectors. The two turbulence reduction screens are located downstream of the honeycomb and are spring-tensioned, six-mesh, 304 stainless steel screens using 0.041-inch diameter wire. A screen cleaning system consisting of piping and nozzles around the top half of each screen is used to deliver a solvent spray during maintenance periods.[1,2]

The Wide-Angle Diffuser (WAD) is located in the 11-By 11-Foot Tunnel drive leg, downstream of the compressor and annular diffuser and directly upstream of the tunnel aftercooler. The WAD has a 60-degree included angle. The flow in the WAD region was studied extensively before modernization and exhibited a highly separated jet flow characteristic. Unsteady separated flow in the annular diffuser coupled with WAD jet flow was identified as one of the sources of test section low frequency Mach number fluctuations. In order to eliminate this flow unsteadiness and improve the WAD diffusion process, passive flow enhancement structures were introduced into the annular diffuser and the WAD. Flow deflector flaps are mounted to the annular diffuser nacelle to deflect the flow toward the outer wall and reduce separation. Annular turning vanes are installed at the entrance to the WAD to turn the flow toward the wall of the WAD. Scale-model tests of the flap and turning vane concepts were completed during the design phase of the project. This testing validated the effectiveness of the approach in reducing the low-frequency fluctuations and improving diffuser flow attachment.[3]

The flexible wall (flexwall) in the 11-By 11-Foot Transonic leg provides the converging-diverging nozzle which creates supersonic flow in the slotted-wall test section. The original flexwall had problems with dynamic stability during transition through certain tunnel conditions and was found to have cracks in several critical structural welds. The two-dimensional nozzle side walls are eleven feet high by approximately twenty feet long with a variable thickness along the length of the wall. The flexwall is fixed at the downstream end and positioned at the upstream end by a jacking system. The thickness distribution along the wall varies in order to produce the best wall contour for the development of supersonic flow in the test section. Two new intermediate jack stations were added to improve the control of the nozzle contour and to increase stability. The new flexwall was fabricated from $17-4 \mathrm{PH}$ stainless steel. An analytical study using a Method of Characteristics (MOC) code coupled with a structural model was completed in order to define a thickness distribution which would produce the optimum nozzle contour for supersonic flow entering the test section, Figure 3.

\section{Flexible Wall Nozzle Thickness Distribution}

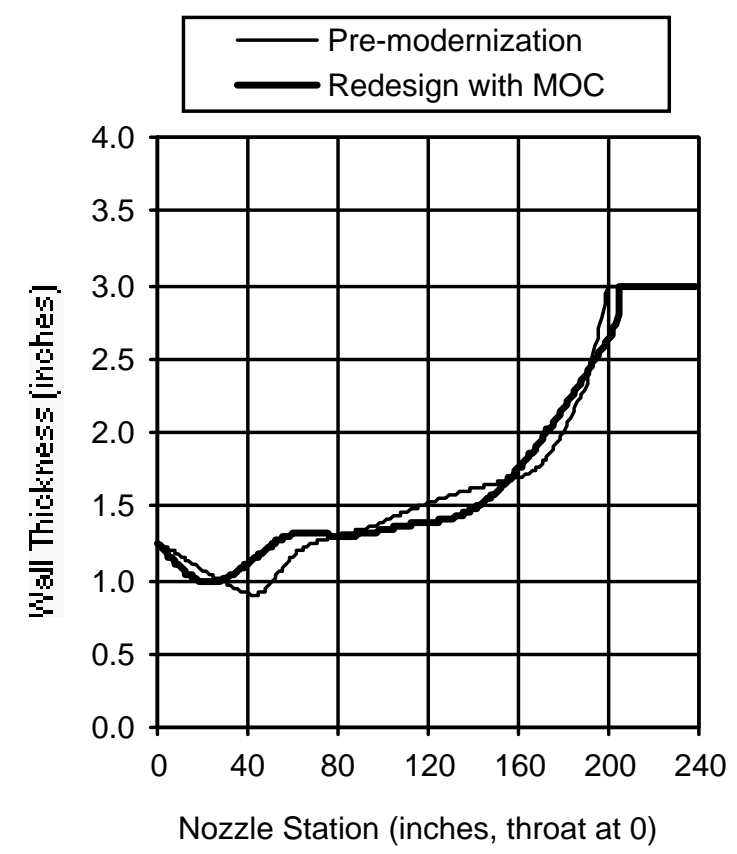

Figure 3. Flexible Wall Nozzle Thickness

\subsection{1-BY 11-FOOT TURNTABLE}

The main objective of the turntable replacement was to provide a higher capacity turntable model support system to accommodate large semi-span models. The approach included providing a 
commercial rotary indexing table with modifications to fit the wind tunnel requirements. This work package also included a floor balance check-loading fixture with hydraulic jacks to allow a balance to be mounted on the turntable and quickly check-loaded before model installation. The turntable control system communicates with the FCS over a digital link.

\subsection{COMPOSITE COMPRESSOR BLADES}

Composite compressor blades were fabricated to replace aluminum blades in the three-stage compressor of the 11-By 11-Foot Tunnel. The composite blades replace existing machined aluminum blades that require significant preventative maintenance. The aluminum blades are also subject to high resonant stresses within the operational speed ranges of the three-stage compressor. Avoiding these resonance zones decreases the productivity of the tunnel. The composite blades were designed to operate anywhere in the operational range, including on resonance.

Prototype blades were conceived, designed, manufactured, and tested at Ames over a fouryear period from 1990 to 1994 . The new blades consist of an carbon/epoxy lay-up (36 layers) over a syntactic foam core. In the root area, where the blade mounts into the compressor disk, the skin and core flare out to provide a mechanical as well as an adhesive joint inside a fiberglass root block. The root block is molded from fiberglass cloth layup 1/2-inch thick and attached to the blade with a mixture of chopped glass fiber and epoxy resin. The use of this sandwich construction provides exceptional damage tolerance for the carbon/foam assembly. The outer surface of the blade is covered with two layers of fiberglass cloth to aid in the detection of impact damage.

Engineers from Ames developed the concept for the blade design. Extensive material tests were conducted to determine the allowable loads, strength characteristics, and damage tolerance of the carbon epoxy skin assemblies. The craftsmen in the Ames Model Shop constructed three prototype blades. One prototype blade was statically tested to failure in the Test Engineering Laboratory at Ames. The overall strength of the blade assembly was 6.2 times the maximum operating load required. Two other blades were operationally tested in the three-stage compressor for a year. These blades were removed and examined after a one-year period and no damage or surface distress was found. One complete set and approximately one-third of a set of spares were manufactured and delivered to Ames as part of the UPWT Modernization Project.

\subsection{REFURBISHED MUA PIPING SYSTEMS}

The existing Make-Up Air (MUA) system piping was found to have many defective welds. For this reason, it was decided to replace all of the piping "in kind", as well as to replace all of the system control valves and instruments. This effort also included refurbishment of the compressor bearing lubrication oil systems and a new MUA gas-fired air dryer with dual desiccant towers and a closedloop regeneration system. Over 170 air, water, and oil valves which range in size from onequarter to thirty-six inches were replaced.

\subsection{REFURBISHMENT OF THE MUA MOTOR}

The MUA compressor drive motor is located in the Auxiliaries equipment building on the UPWT site. The 15,000-horsepower motor drives a four-stage, low-pressure, centrifugal compressor, and a seven-stage, high-pressure centrifugal compressor mounted in tandem. The motor drives the low stage through a Farrel speed-increasing gear (318/4200 RPM). The high stage is mechanically coupled directly to the low stage. The compressor provides 50,000 standard cubic feet per minute of air to the UPWT or the 12-Foot Pressure Wind Tunnel at Ames.

The scope of this refurbishment effort consisted of on-site inspection and preventative maintenance of all major motor components. This included replacement of all stator wedges, balance weights, slip rings, and brush assemblies. The motor stator was shifted to expose the rotor and stator windings for inspection. The intent of this work was to extend the service life of the MUA compressor drive motor for twenty additional years of reliable operation.

\subsection{COOLING TOWER AND CIRCULATION WATER PIPING}

The main objective of this effort was to replace the original redwood cooling tower with a modern Fiberglass Reinforced Plastic (FRP) tower of similar capacity. The original ten-cell redwood tower was demolished and removed, except for the concrete water basin. The new FRP tower is an induced-draft, six-cell, counter-flow type and covers approximately two-thirds of the old tower 
footprint. It operates through a stand-alone Programmable Logic Controller (PLC), which communicates over a digital link with the FCS. The original water circulation system, including motors and pumps, was retained.

The original pipes which deliver cooling water to both tunnel aftercoolers and many auxiliary heat exchangers were found to have significant deterioration in their linings and corrosion of metal surfaces. Because of this, approximately 1700 feet of circulating water pipe, varying in diameter from 24 inches to 42 inches, was coated internally to extend useful life. The pipe was first sandblasted. Then a 60-mil layer of soft, warm Urethane was applied to the interior of the clean pipes. This treatment dried into a durable and long-lasting surface which will preserve the integrity of the circulating water system. A number of strainers were also installed at critical points in the system to protect heat exchanger pipes from debris due to corrosion.

\subsection{FACILITY WELD REPAIRS}

Original construction of the UPWT was assumed to be completed in conformance with the ASME Boiler and Pressure Vessel Code, but the vessels were not Code stamped. The shell plates were made primarily from A285 Grade B steel, though other materials were used due to limitations on the availability of this material. The main plates vary in thickness from $5 / 8$ to 2 inches. Shell diameters range from 24 to 70 feet. The primary welding processes used in fabrication of the tunnel were Shielded Metal Arc Welding (SMAW) and Submerged Arc Welding (SAW). The exterior of the 11-By 11-Foot leg is coated with red lead primer and an aluminum top coat. The exterior of the two supersonic legs had been painted with an epoxy primer and a polyurethane top coat over the basic coating described for the 11-By 11-Foot leg.

The pressure vessel weld repair portion of the project arose out of a centerwide effort to recertify all major pressure vessels. Initial assessments of the welds and the pressure vessel material demonstrated that the UPWT pressure vessel system could be repaired, rather than replacing the entire shell as was done to the 12-Foot Pressure Wind Tunnel at Ames. Defects in butt and fillet welds were found during Nondestructive Examination (NDE) periods from 1989 through 1992 by Radiographic (RT), Ultrasonic (UT), Magnetic Particle (MT) and Visual (VT) inspection techniques. NDE of the butt welds in the shell exposed 9,586 feet of defective welds out of a total length of 35,206 feet, for a combined reject rate of $27 \%$. The reject rate was $34 \%$ in the $11-B y$ $11-F o o t$ leg, $16 \%$ in the 9-By 7-Foot leg, and 32\% in the 8-By 7-Foot leg. Magnetic particle inspection of 15,309 feet of fillet welds, out of a total facility length of about 56,000 feet, indicated reject rates of only $0.08 \%$. Repair and NDE of the welds was completed during the shutdown periods associated with each of the wind tunnel legs.

\subsection{MAIN DRIVE SPEED CONTROL SYSTEM}

The objective of this portion of the project was to replace the twenty-year-old Main Drive Speed Controller (MDSC) electronics with a programmable, microprocessor-based control system to regulate the four main drive, woundrotor, induction motors and liquid rheostat systems. Simulations of the motor mechanical and electrical systems were completed prior to the design phase to predict the performance characteristics of the new controller. The mechanical hardware for the liquid rheostat systems for each motor was retained. The pilot motors that control the height of the plates in the rheostat tanks were replaced, along with all associated instrumentation to control the rheostat electrode position. The new system consists of a PLC that communicates through a link to the FCS at each tunnel and at the Auxiliaries facility. The PLC provides commands to redundant controllers for each drive motor pilot motor and a dynamic braking generator field controller. This task also included replacement of all speed sensing systems, transmitters, signal converters, interfaces, and other MDSC devices. The MDSC electronics and motor controllers are located in an 8-by 14-foot enclosure located within the switchgear building.

\subsection{MAIN DRIVE MOTOR REWIND}

The main objective of this effort was to rewind the four main drive motors to provide long term reliability and to increase their power capability. The original motors were rated at 45,000 horsepower, for 60 cycle, 6,900 volt, 3-phase power. Full load speed was $685 \mathrm{rpm}$ and synchronous speed was $720 \mathrm{rpm}$ with an 80 degree Celsius allowable temperature rise. Each original motor had a one hour capability of 54,000 horsepower from a cold start. Each motor has two electrically-separate stator circuits brought out on separate winding terminals. The approximate weight of each rotor is 69 tons, while each stator 
weighs approximately 50 tons. The bearing pedestals weigh approximately 9 tons each. A cooling system provides $128,000 \mathrm{cfm}$ of air to the motors. A ventilation system for the slip rings and brush rigging draws 3,840 cfm of ambient air from the motor room and exhausts it to the outside.

The rewound motors are capable of producing 65,000 horsepower at $695 \mathrm{rpm}$. The 180 coils in each rotor and 210 coils in each stator were replaced. The motors were rewound with Class F insulation at a factory facility. The effort also involved installation of new slip rings, brush holders, and brushes. The nameplate rated primary current of 4,525 amperes is required to produce 65,000 horsepower. However, the existing air circuit breakers are limited to a maximum current of 2,000 amperes each. Since there are two breakers per motor, the maximum continuous operation of the motors are currently limited to approximately 59,000 horsepower.

The main drive motor bearing lubrication system was also replaced and includes new pumps, motors, immersion heaters, valves, and piping to the bearings. The original flow switches in the main drive motor room were replaced with flow indicating transmitters.

After inspection for wear, the eight motor journal bearings, two journal bearings associated with the compressors, and the motor thrust bearing shoes were rebabbited. In addition, the existing bearing oil lines were hydroflushed and then flushed with hot oil to remove any deposits in the lines.

The motors were removed from the motor house and reinstalled by means of several large capacity mobile cranes. The rotors and stators were separated at the site before shipping to the rewind facilities, and reassembled before reinstallation. A hydraulic gantry system was installed in the motor house in order to shift the disconnected motors to a position in the motor house from which they could be removed. A platform was assembled outside the motor house on which a crawler crane with a 70-foot boom and 150-ton capacity was positioned. The crawler crane picked the motor out of the motor house and set the motor assembly on a fixture on the ground. The rotors were removed from the motor assembly on a large stator shift fixture. Another 100 ton mobile crane moved both the rotors and stators to trucks.

\subsection{REFURBISHED DRIVE MOTOR} SWITCHGEAR
The switchgear modernization involved refurbishment of the original facility breakers to provide long term service. These circuit breakers are used to supply power to the main drive motors, the power factor correction capacitors, and the transformers. Fifteen original 1200-amp and two 2000-amp air circuit breakers were modified to sulfur-hexafluoride (SF6) gas insulated circuit breakers for the capacitor and distribution transformer loads. Pressure relays were installed in the SF6 breakers to monitor for low SF6 pressure. Ten original 2000-amp and four 1200amp GE Magna-Blast air circuit breakers were refurbished to the original manufacturers specifications for the main drive motors and the MUA system. This work included removal and disposal of asbestos arc chutes from these breakers.

\subsection{FACILITY TRANSFORMERS}

The two main transformers (T45 and T46) that feed the entire UPWT facility, including the four main drive motors, were tested after the facility shutdown and found to have internal damage. The original transformers were rated at $86,750 \mathrm{kva}$ with a $110 \mathrm{kv}$ primary voltage and a $6.9 \mathrm{kv}$ secondary voltage. The transformers were rewound and their cores replaced. The refurbished transformers were upgraded to a $115 \mathrm{kv}$ primary voltage, a $7.2 \mathrm{kv}$ secondary voltage, and a 97,160 kva rating. The new iron core for each transformer weighs 82,000 pounds and the copper winding 33,000 pounds. Each transformer holds 6,000 gallons of oil.

\section{11-BY 11-FOOT ACTIVATION}

The primary objective of the Integrated Systems Test (IST) was to safely demonstrate and document the post-modernization capabilities of the 11-By 11-Foot Tunnel. Other objectives were to verify the safe operation of the tunnel, to verify the performance of tunnel systems, to verify the Standard Operating Procedures (SOP), and to define the operating envelope.

\subsection{INTEGRATED SYSTEMS TEST OBJECTIVES \\ 3.1.1. VERIFICATION OF SAFE OPERATION}

All major subsystems had been extensively tested prior to the start of the IST. The Facility Control System (FCS) and the Hard-Wired Safety System 
(HWSS) had also been thoroughly checked to the fullest extent possible. Component and subsystem tests functionally verified systems short of pressurizing the facility or rotating the tunnel compressor for wind-on operations. During the IST, stresses and loads on new and refurbished tunnel structures were continuously monitored and documented as the tunnel envelope was expanded.

\subsubsection{VERIFICATION OF PERFORMANCE}

The mechanical, electrical, and aerodynamic performance of the facilities was measured and documented. The performance of equipment, such as the three-stage compressor, was established to provide a baseline for future operations. Tunnel performance parameters, such as circuit pressure loss, compressor compression ratio, and test section flow quality, were also key factors in documenting the improvements due to modernization.

\subsubsection{VERIFICATION OF STANDARD OPERATING PROCEDURES}

The Standard Operating Procedures (SOP) manuals for each facility were developed by the technical writing staff and reviewed extensively by a team of system owners and experts. The preoperating, operating, postoperating, and emergency procedures were evaluated and validated during the IST. Each procedure and mode of operation was verified and the manuals were revised to reflect the true operation of the facilities.

\subsubsection{DEFINITION OF OPERATING ENVELOPE}

The maximum unit Reynolds number of the 11-By 11-Foot Tunnel is limited by the design rating of the pressure vessel and the power of the drive motors. The pressure vessel limit did not change, but the rewinding of the main drive motors allows continuous operation at full power. The premodernization motors had a combined output of 180,000 horsepower for continuous operation, or 216,000 horsepower for one hour after a cold start. The present limit for continuous operation is 236,000 horsepower. The maximum tunnel empty Mach number of 1.5 remained unchanged; however, the minimum Mach number is now 0.20 due to improvements in the Main Drive Speed Control system.

\subsection{INTEGRATED SYSTEMS TEST RESULTS}

The IST was divided into distinct phases that demonstrated different capabilities of the facility. The first phase of the IST involved the functional checkout of the mechanical and automation systems of the MUA system. The second phase of the IST focused on the wind-off performance of the tunnel, primarily safety systems and pumping and evacuation times. The first two phases will not be discussed in detail. Subsequent phases which focused on enlarging the operational envelope were named Subsonic Operation (Phase 3), Subsonic Performance (Phase 4), Flow Quality Performance (Phase 5), Supersonic Operation (Phase 6), and Supersonic Performance (Phase 7).

\subsubsection{SUBSONIC OPERATION}

The primary objectives of the Subsonic Operation Phase (Phase 3) were to operate the tunnel over the entire subsonic envelope up to the maximum total pressure, to monitor the internal tunnel structures, to demonstrate initial operation of the four main drive motors, and to clean the tunnel before installation of the composite compressor rotor blades. Phase 3 was started on November 4 and completed on December 23, 1998. Existing aluminum compressor rotor blades were used for this phase.[4] The new internal structures performed well, and none of the structures or components approached critical stress or deflection values. The Main Drive Speed Control (MDSC) system was tuned, and the major functions of this system were checked out. All four drive motors were activated and performed well under local control from the MDSC. Drive speed stability after preliminary tuning of the system was about $\pm 1 \mathrm{rpm}$ at the drive speed set points. The tunnel pressure control system was tuned and performed well at total pressures from 14.7 psia to the maximum of 32 psia. The emergency shutdown functions and processes were also exercised and worked well. After operation at Mach numbers from 0.35 to 0.94 at total pressures from 14.7 to 32 psia, all factors indicated that the tunnel was clean enough to install composite blades and continue with the next testing phase.

\subsubsection{SUBSONIC PERFORMANCE}

A variety of mechanical, electrical, and automation work was completed during the shutdown period, which preceded Phase 4 wind-on testing. Phase 4 started on December 28, 1998 and was completed 
on September 3, 1999. At the beginning of this phase, the composite compressor rotor blades were installed, the turbulence reduction screen seams were repaired, and the main drive motor slip rings were machined.

The two turbulence reduction screens installed in the settling chamber had developed rips in the seams prior to the start of the IST. This had occurred approximately 18 months after the screens were first tensioned. Each screen has four seams that are offset six degrees from horizontal. Four of the seams that had either partially "unzipped" or showed signs of failure were repaired before the start of the IST. The other seams were temporarily repaired with a "patch" which consisted of a six-inch strip of backing screen centered about the seam and bolted to the main screens. This allowed initial operations to continue during Phase 3 . The remaining four seams were replaced during the composite rotor blade installation at the beginning of Phase 4.

The screen seam failure was determined to be caused by corrosion in the crevices of the brazed joint due to zinc contamination and multiple reheating cycles during fabrication. The zinc contamination occurred as a result of the joint fabrication process during which zinc oxide sanding paper was used to prepare the wire surface before brazing. When the joint was brazed, the zinc residue on the wires diffused into the bronze alloy. Upon cooling, a zinc rich phase formed at the wire braze boundary, which was attacked by corrosion until it failed. The final repair of each seam involved removing one screen mesh on each side of the brazed joint. The horizontal wires were pulled together and then each vertical wire was welded. Welding wire was added to the joint to guarantee a full penetration weld on each wire. The weld repair resulted in a seam thickness equivalent to two wire thicknesses, whereas the brazed seam had been about one and one-half wire thicknesses. All of the repair work was completed in place by the Ames shops in a timely and effective manner.

The primary objective of Phase 4 was to evaluate the aerodynamic and structural performance of the composite rotor blades over the entire subsonic envelope of the tunnel. Secondary objectives were to continue to monitor the internal tunnel structures, to establish new drive speed setpoints based on the rotor blade evaluation, to establish the minimum stable tunnel Mach number, and to determine the compressor operating loads at new speed setpoints. The compressor was evaluated with drive speed run-ups to sonic test section conditions at the extreme positions of the Inlet Guide Vanes (IGV) and at total pressures from atmospheric to the maximum of $32 \mathrm{psia}$. The rotor blade stresses due to resonance were identified during these operations. Strain gages were installed on 5 rotor blades in each of the three stages. One heavily instrumented blade in each stage was instrumented with strain gages to monitor the first four bending modes, the first edgewise bending mode, and the first three torsion modes of the blade directly. Four lightly instrumented blades in each stage were instrumented with strain gages to monitor the second torsion and third bending modes directly. Modal participation factors were developed through pre-test modal testing and used to estimate the stresses on the lightly instrumented blades. The static and dynamic stresses on the rotor blades were all below the critical (red line) stress values at the maximum total pressure of 32 psia and with the IGV's at their home position of 19.5 degrees, Figure 4. The major bending and torsion modes are noted on the figure.

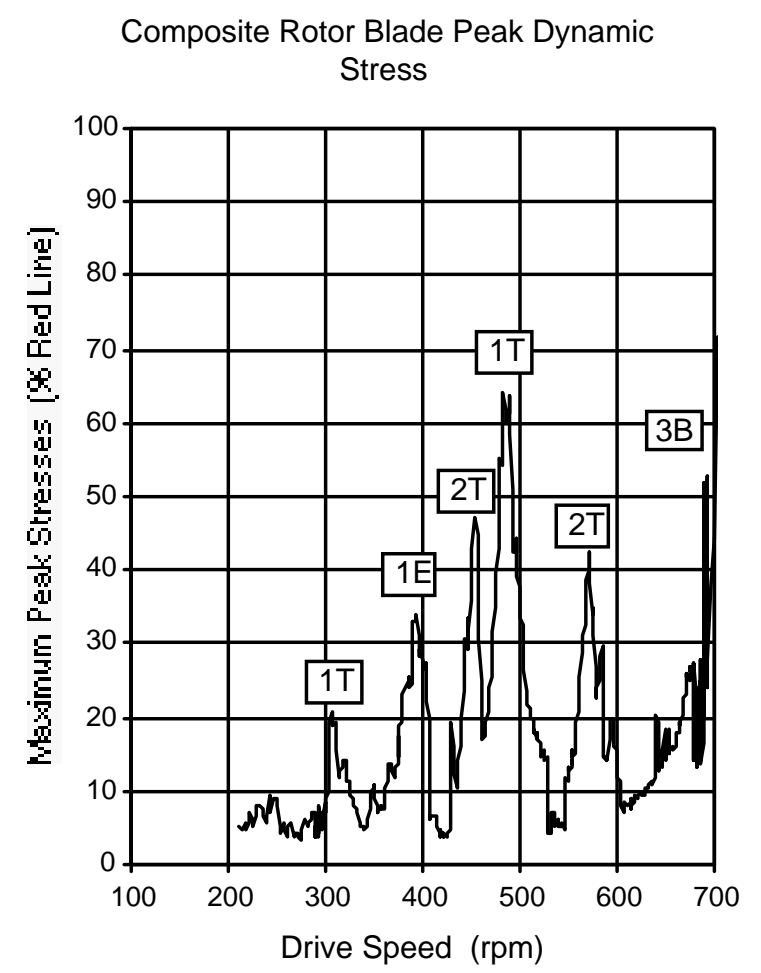

Figure 4. Composite Rotor Blade Dynamic Stresses 
The four rewound main drive motors were operated to a top speed of $700 \mathrm{rpm}$, a significant increase from the $585 \mathrm{rpm}$ attained during the previous phase of the IST. The motors performed at and above the design specifications, and evaluations of the drive shaft torsional stresses and shaft vibrations continued throughout this phase. The Main Drive Speed Control (MDSC) system was again tuned and the major functions of this system checked. The MDSC liquid rheostat system was adjusted to allow the motors to produce the maximum power available. The repaired turbulence reduction screens were tensioned to their final load to minimize screen deflection. All new internal structures also performed well, with all structures or components below critical stress and deflection values.

On April 21, 1999, a facility-wide electrical trip occurred in the main Ames substation. The tunnel main drive system was running at a drive speed of $562 \mathrm{rpm}$ when the trip occurred, and an automatic tunnel shutdown was initiated. The two primary indications of the fault included a differential current trip related to the secondary side of transformer T46 and a relay trip that measures sudden pressure in the T46 transformer oil tank. Extensive electrical testing and inspections were immediately performed on the transformer. A dissolved gas analysis of oil samples indicated that an internal arc had occurred. The oil was removed from T46 and the core was untanked at Ames for inspection and repair. After untanking, it was found that the tap changer on the bottom primary coil on one of the three phases had sustained an arc while operating in position 2 $(118,000 \mathrm{~V}$ to $7200 \mathrm{~V})$. There are five tap changer positions that accommodate varying input line voltages from utility companies. The tap changer is typically set and rarely changed unless the supply line voltage changes. Based on inspections and a review of the relay tripping sequence, it was concluded that the arcing was constrained within a single phase and did not pass to ground. The tap changer was repaired, and the transformer was reassembled and put back into service.

A thorough inspection of the composite rotor blades was performed during the transformer repair period. One of the 52 third stage rotor blades showed severe cracking in the root block region. The blade was removed and replaced with a spare composite blade. It was determined that the failure was most likely a manufacturing defect in the blade, and the IST continued with the checkout of the composite rotor blades.

Resumption of the operational portion of Phase 4 of the IST started on July 6, 1999, after energization of repaired transformer T46. The root block separation problem with the composite blades did not reappear during this phase of testing. Frequent rotor blade inspections did not show any problems in the 83 hours of Phase 4 tunnel operation after the transformer repair.

A major activity during this time was the checkout and testing of the Main Drive Speed Control (MDSC) system, which went through an intensive software rewrite during the transformer repair to address $\mathrm{Y} 2 \mathrm{~K}$ software and other technical issues. Another problem involved the slip ring brushes on two of the main drive rotors. The brushes on motors one and three were well polished after running at moderate test conditions. However, the brushes on motors two and four were not polished. The brushes on motors two and four were exhibiting breakage and discoloration on the pigtail shunts through which current flows to the brush. The orientation of the brush box hardware was determined to be the cause of the problem. After modifications to the brush boxes, the problem did not reoccur.

\subsubsection{FLOW QUALITY PERFORMANCE}

The Flow Quality Performance Phase (Phase 5) started on September 7 and was completed on September 28, 1999. The primary focus of this phase was to evaluate the subsonic test section flow quality improvement due to the installation of a honeycomb structure and two six-mesh screens in the settling chamber. This test involved installing an eight-foot rake in the test section and populating the rake with temperature, steady-state pressure, unsteady pressure, and hot wire instrumentation. A five-hole cone probe was installed on the rake on a stand-off six inches below the centerline. Subsonic conditions from Mach numbers of 0.20 to 0.95 and tunnel total pressures from 0.5 atmosphere to the maximum pressure of 2.2 atmospheres were tested. Tunnel configurations included a baseline with the tunnel in a normal configuration, one with the floor slots covered to simulate semi-span testing configurations, and a configuration with all of the wall slots taped over. The solid wall configuration was tested to document a baseline for potential slot baffle improvements in turbulence and acoustics. The horizontally instrumented rake was 
traversed vertically to survey a cross section of the tunnel from 14 inches to 93 inches above the test section floor. The tip of the cone probe was at tunnel station 163.6 and the other probes at tunnel station 185.

The five-hole cone probe provided simultaneous upflow and crossflow data across a variety of test conditions. The cone probe was calibrated during the early running by pitching the model support to develop slope and offset values. Premodernization flow field survey data with the test section in a solid floor configuration showed indications of a flow perturbation near the lateral centerline, 40 inches above the floor, with a crossflow gradient of up to 0.6 degrees. Phase 5 IST data taken with the same tunnel configuration show that this phenomenon has been eliminated. Preliminary crossflow data show that the variations are within \pm 0.08 degrees.

Turbulence data show that at a Mach number of 0.80 , the baseline turbulence level has been reduced from $0.32 \%$ to $0.25 \%$ at a nominal total pressure of one atmosphere, Figure 5 . With all test section slots covered, the turbulence is further reduced to $0.12 \%$. The turbulence gradient throughout the test section was also noted to be much more uniform than the pre-modernization levels. Amaya and Murthy describe the instrumentation and methods and report the flow angularity and turbulence results from this phase in detail. [5]
Turbulence Data from IST

@ centerline, PT = 2200 psf

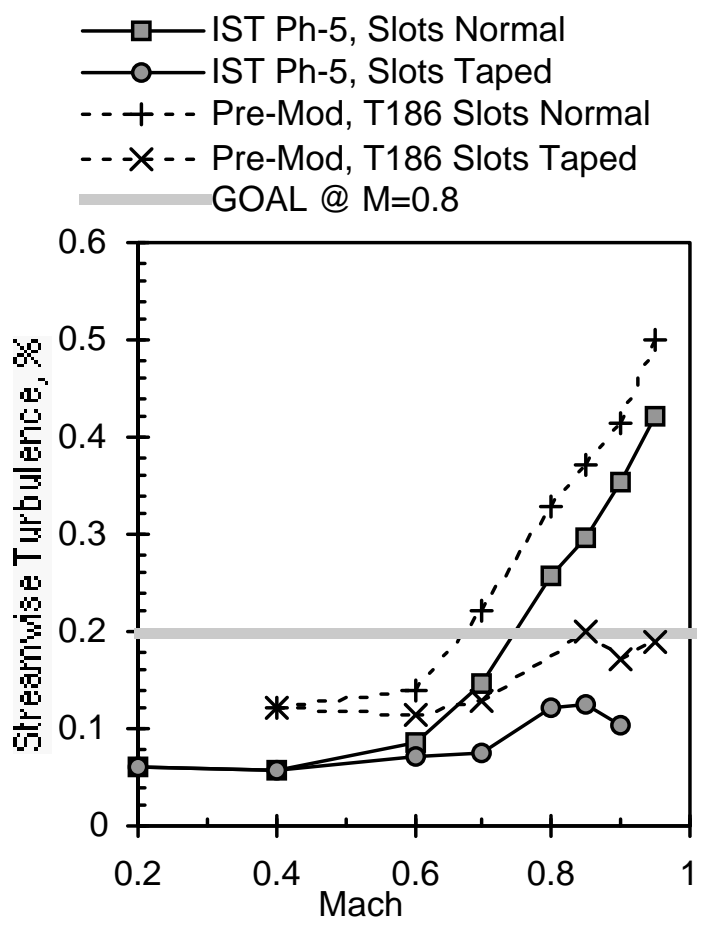

Figure 5. Comparison of Pre-modernization and Post-modernization Turbulence Levels

\subsubsection{SUPERSONIC OPERATION}

The Supersonic Operation Phase (Phase 6) of the IST was started on September 29 and completed on October 22, 1999. The primary focus of this phase was to evaluate the structural performance of the new flexible wall nozzle (flexwall) during supersonic operations. Two new jack stations were added to stabilize the flexwall at nozzle stations 60 and 140 inches downstream of the throat. The flexwall thickness was designed to set the optimized contour using the thrust block jacks at the throat station and the two new jack stations.

The first supersonic runs at one-half and one atmosphere were performed using the nozzle contour settings from the original flexwall to check structural loads before using the new contour setpoints. These Mach number sweeps did not initially attain the test section Mach number setpoints associated with the nozzle geometry. However, old flexwall throat positions were eventually verified after modifying the method of 
setting the Mach number by maintaining the minimum compression ratio to establish the supersonic Mach number.

After multiple series of supersonic runs, a full composite compressor blade inspection was performed, and damage to three third-stage rotor blades was observed. The compressor clamshell was opened and a detailed inspection of all rotor blades performed. The inspections revealed that all the damaged blades were located in the third stage of the compressor. Three blades had epoxy resin material from the root block missing. In addition, fifteen other blades exhibited cracking at the blade and root block intersection that was beyond the threshold for in-place repair. The compressor temperature, particularly at the third stage, was much higher at the compression ratio required to achieve supersonic flow. These temperatures were normal, however, this was the one major parameter that had not yet been encountered in the tunnel envelope exploration. The composite blades were removed and aluminum blades were installed to proceed with the next IST phase.

\subsubsection{SUPERSONIC PERFORMANCE}

The Supersonic Performance Phase (Phase 7) was started on October 25 and completed on December 4, 1999. The primary objective of this phase was to evaluate and document the aerodynamic performance of the new flexible wall nozzle. In addition to evaluating the supersonic performance of the tunnel, the subsonic envelope was again validated with aluminum compressor rotor blades installed and with damping tape in the dovetail connection to the rotor disk. The performance of the flexwall was evaluated by measuring the test section Mach number distribution. The test section Mach number distribution was measured using a calibration pipe with static pressure taps every three inches throughout the test section region. The pipe is supported by four cables attached to the upstream end of the pipe in the contraction region. The downstream end is attached to the Sting Model Support System (SMSS) downstream of the test section. A hydraulic cylinder at the downstream end of the pipe provides tension to reduce the pipe bow.
Drive speed run-ups and IGV sweeps at a constant compressor drive speed were performed to verify the dynamic stresses in the aluminum compressor rotor blades throughout the subsonic regime. The allowable operational drive speeds were assigned to avoid speeds at which the blade dynamic stresses are at their peak, Figure 6 . The major bending and torsion modes are noted on the figure. The compressor drive speed is used to set a coarse Mach number, and the Inlet Guide Vanes are varied to control Mach number within a certain range, Figure 7.

Aluminum Rotor Blade Peak Dynamic Stress

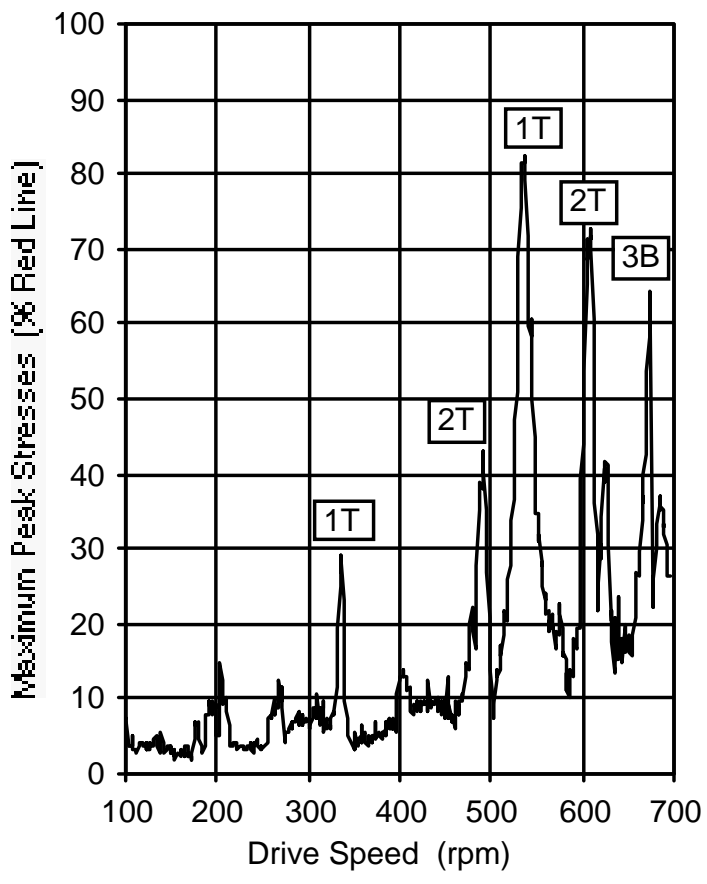

Figure 6. Aluminum Rotor Blade Dynamic Stresses 
Mach Number Operating Chart

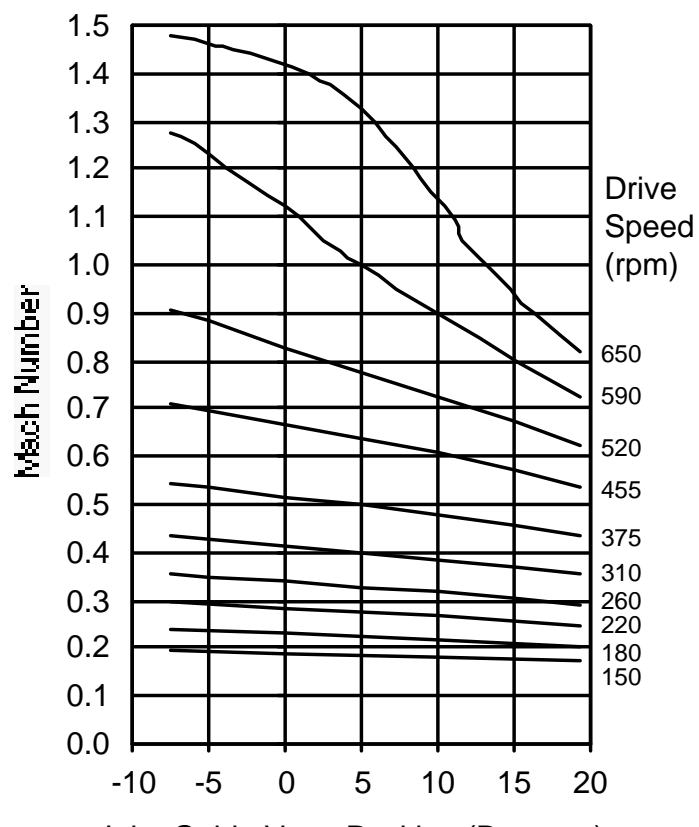

Inlet Guide Vane Position (Degrees)

Figure 7. Drive Speed and Inlet Guide Vane Operating Chart

The jack at the nozzle throat of the flexible wall and the two new jack stations were positioned for a given Mach number using setpoint tables in the Facility Control System. The evaluation of the flexwall began by using the pre-modernization Mach number setpoint table for the throat position and measuring the test section Mach number distribution. Initial runs demonstrated that the tunnel compression ratio can have a significant effect on the test section Mach number distribution. Therefore, a process was developed to consistently achieve a Mach number setpoint by using the minimum compression ratio to establish supersonic test section conditions. This process guarantees that the test section Mach number distribution is level for each Mach number setpoint.

The final optimum throat settings were very similar to the original flexwall setpoint table used with the old flexwall. However, to achieve a better test section Mach number distribution between Mach numbers of 1.25 and 1.35 the setpoints were adjusted, Figure 8 . In addition, by validating the
Method of Characteristics (MOC) analysis with actual flexwall position and Mach number distributions, the flexwall contour was further optimized at the midstream (nozzle station 60 inches) and the downstream (nozzle station 140 inches) jack stations, Figures 9 and 10. The MOC code could not be run reliably below a Mach number of 1.3; therefore, the optimized setpoints were extended by extrapolation down to the 1.06 Mach number condition where the flexwalls are parallel.

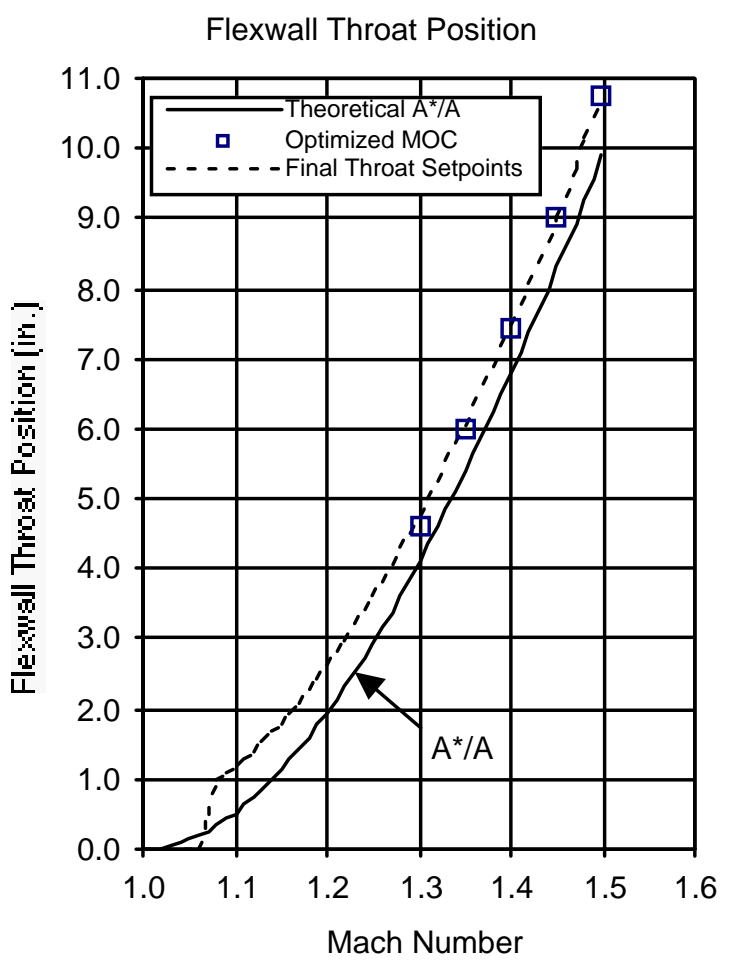

Figure 8. Flexwall Throat Postion Setpoints 
NS 60 Jack Position Setpoints

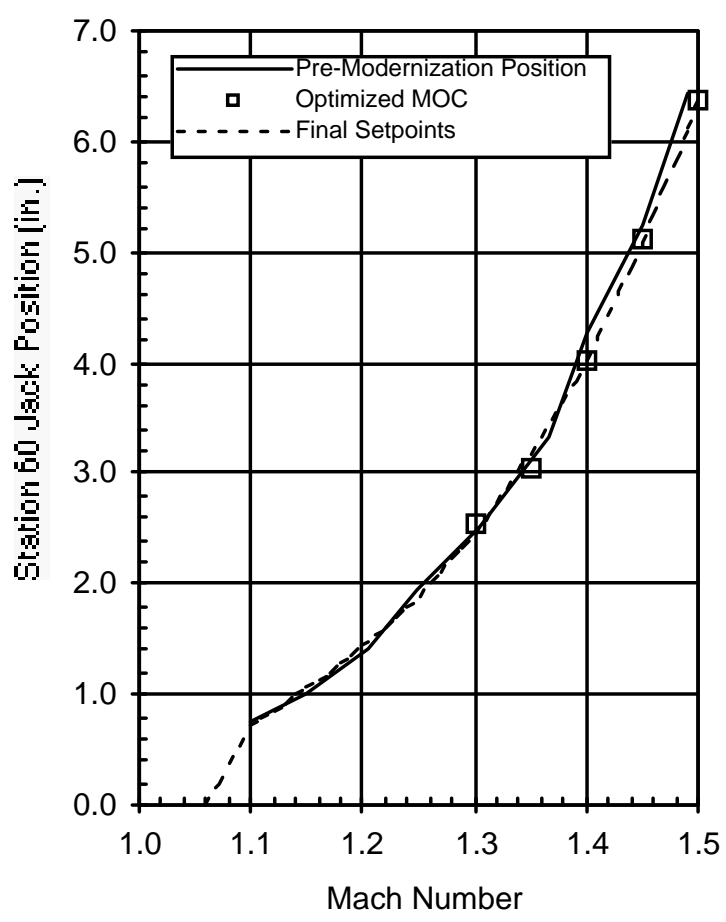

Figure 9. NS 60 Flexwall Jack Position Setpoints

NS 140 Jack Position Setpoints

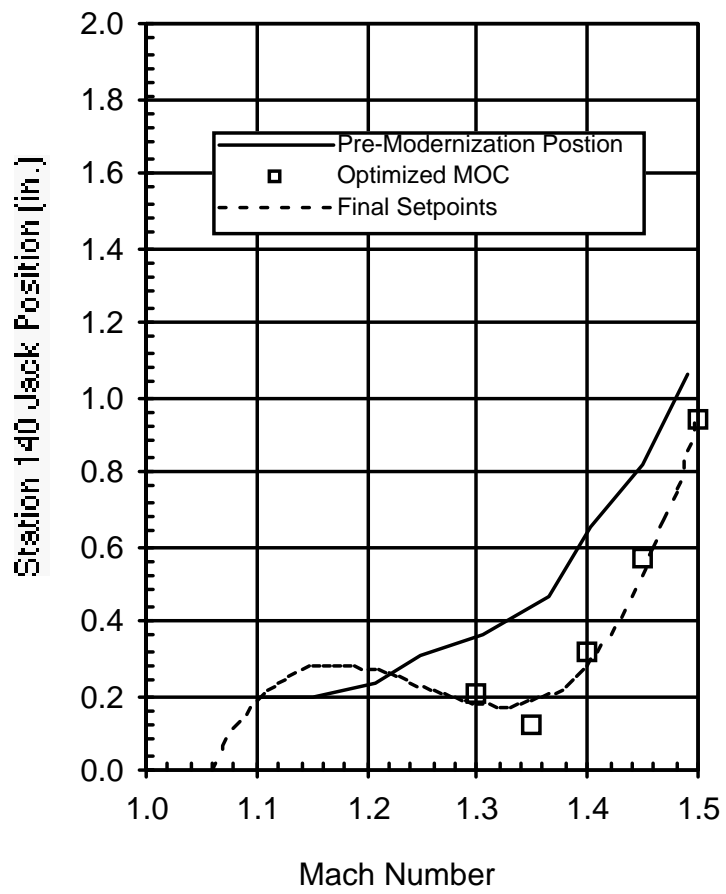

At a tunnel total pressures of 22 psia the maximum Mach number of 1.5 was achieved with the static pipe in the test section. However, at the maximum tunnel total pressure of 32 psia, the maximum Mach number was limited to 1.34 due to the available drive power. The main drive circuit breaker allowable current limits each motor to 44 megawatts for a total available drive power of 176 megawatts. The maximum Mach number at full power and maximum total pressure is therefore limited to 1.34, Figure 11. This chart does not include the approximately 4 to 12 megawatts used to power the MUA compressor. The slight loss in the maximum Mach number at the maximum total pressure is attributed to the increased circuit losses associated with the new honeycomb and screen installation. The complete tunnel empty operating envelope developed throughout the IST is shown in Figure 12.

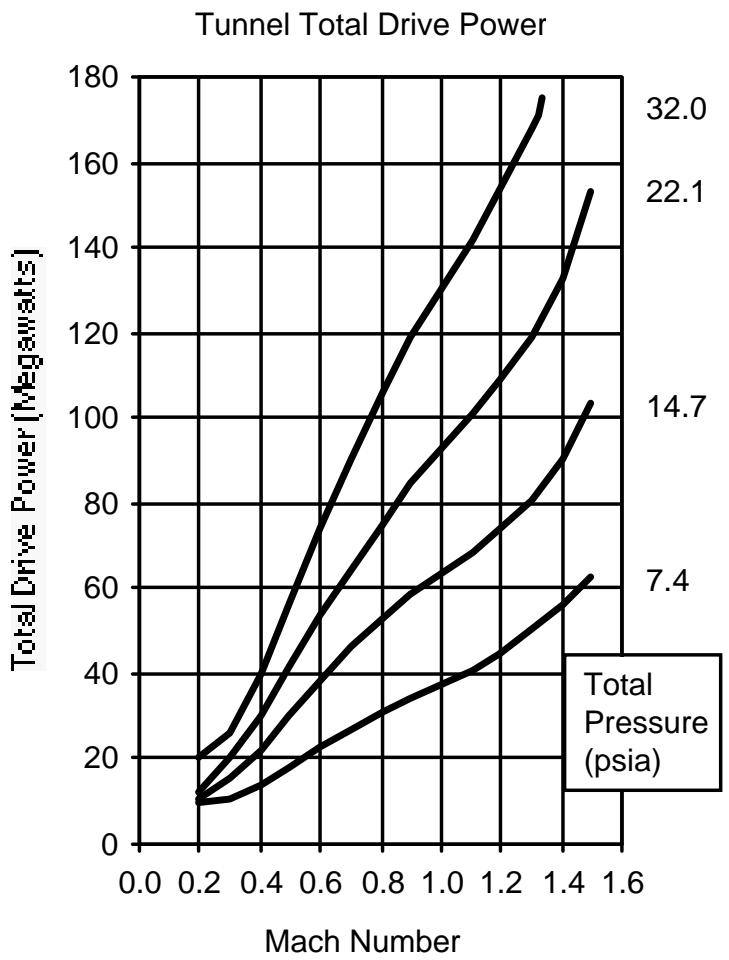

Figure 11. Total Tunnel Drive Power

Figure 10.NS 140 Flexwall Jack Position Setpoints 
TUNNEL OPERATING CHARACTERISTIC

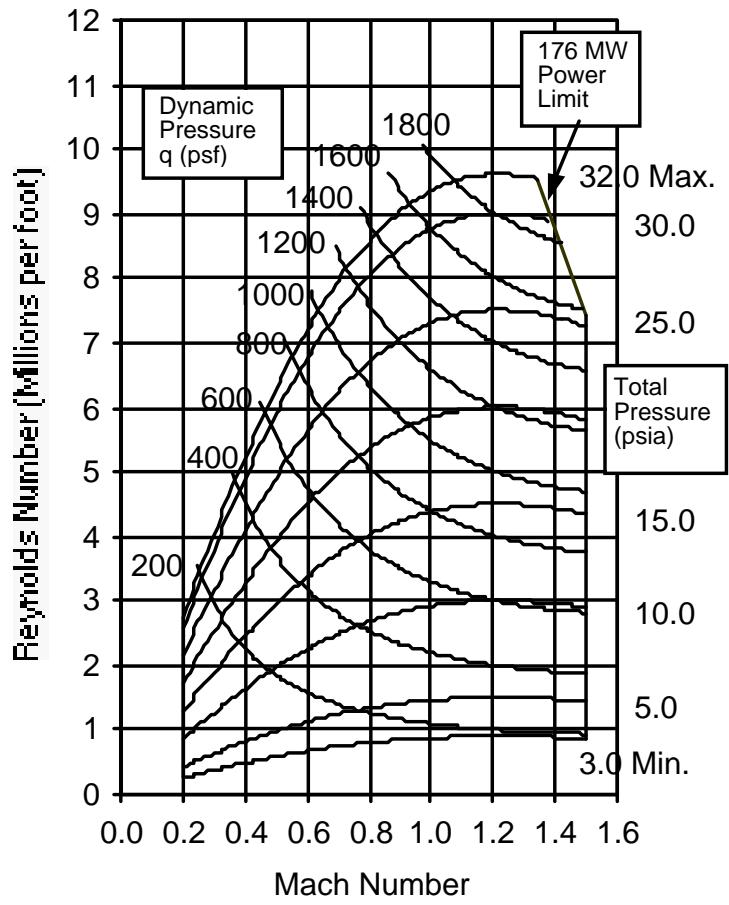

Figure 12. Operating Characteristics of the 11-By 11-Foot Transonic Wind Tunnel

\section{CALIBRATION AND VALIDATION TESTS}

Two calibration tests have been completed and two validation tests will be performed before the first production test. The first calibration test was the Mach number calibration of the test section using the static pipe apparatus. The calibration pipe remained in the test section after the Supersonic Performance Phase of the IST. The tunnel was calibrated on centerline throughout the entire subsonic and supersonic regime at four total pressures, nominally $0.5,1.0,1.5$, and 2.2 atmospheres. The pipe was then lowered to midway between tunnel centerline and the floor and the slots on the floor sealed to calibrate the tunnel for semi-span model configurations. The complete tunnel Mach number envelope was again calibrated in this configuration. The Ames subsonic calibration model, identified as the LB435 model, was then installed and tested to measure the integrated flow angularity, to compare aerodynamic performance results with pre-modernization data, and to validate the model support system operation with an airplane model. This test also successfully demonstrated the automated coordination between the test conditions controller and model support controller.
Two airplane model validation tests are in progress to allow comparisons of airplane aerodynamic performance data for models previously tested in the 11-By 11-Foot Tunnel. A typical commercial transport model and a military fighter were selected to test procedures and processes. A 3.7\%-scale Boeing 777 model and an $8 \%$-scale Boeing F/A-18E model are being tested to validate the readiness of the 11-by 11Foot Transonic Wind Tunnel for production testing.

Several other future calibration tests are also planned to fully document the tunnel flow quality. A shock reflection study will be performed to evaluate the shock reflection characteristics of the test section at low supersonic speeds. A Flow Uniformity test is also planned to map the flow angularity, total temperature, and total pressure over a greater volume of the test section than was done during the IST. In addition, a Turbulence and Acoustics test is planned to gather more detailed flow quality data throughout the test section volume.

\section{CONCLUSION}

The UPWT Modernization Project successfully completed a significant upgrade in capability and reliability to an aging UPWT facility. The project coordinated the efforts of a diverse group of construction contractors and Ames technical staff. A variety of complex technical challenges were overcome to serve the needs of the aerospace community for years to come.

The activation testing of the 11-By 11-Foot Transonic Wind Tunnel and the Auxiliaries facility was successful in demonstrating the modernized capabilities of the UPWT facility. Significant increases in flow quality, productivity, and reliability were demonstrated by the IST. The calibration tests further prepared the 11-By 11Foot Tunnel for production airplane model testing by means of a thorough test section Mach number calibration. The LB-435 calibration model test verified additional testing processes in preparation for validation and production testing. The two airplane validation tests are in progress and should further demonstrate the readiness of the 11-By 11-Foot Transonic Wind Tunnel for future testing. The achievements of the modernization and activation efforts are due to the outstanding work of the UPWT engineering, technician, and 
craft staff whose dedication made success possible.

\section{REFERENCES}

1. Murthy, S.V., Kmak, F.J., Boone, A. R., and Muzzio, D.E.: "Test Data Summary Report on Simulation Tests in BLASTANE for Design and Validation of Turbulence Reduction System for NASA Ames 11 FT TWT," NASA ARC document number 327-8910-XT1020, NASA Ames Research Center, Moffett Field, CA, December 1995.

2. Murthy, S. V., Kmak, F. J., and Koss, B. R., "The Design and Installation of a Turbulence Reduciton System For the NASA Ames 11-By 11-Foot Transonic Wind Tunnel," Paper \# 982705, 20 ${ }^{\text {th }}$ AIAA Advanced Measurement and Ground Testing Technology Conference, Albuquerque, NM, June 15-18, 1998.

3. Murthy, S.V., Kmak, F.J., Boone, A. R., and Muzzio, D.E.: "Test Data Summary Report on Simulation Tests in BLASTANE for Design and Validation of Flow Conditioning Systems for Annular and Wide Angle Diffusers in NASA Ames 11 FT WT," NASA ARC document number 327-8910-XT1016, NASA Ames Research Center, Moffett Field, CA, April 1995.

4. Nguyen, N., Guist, R., and Muzzio, D. E., "Experimental Investigation of the Rotor Blade Vibration in the Three-Stage Compressor of the 11-By 11-Foot Transonic Wind Tunnel", AIAA 95-3139, 1995.

5. Amaya, M. A., and Murthy, S. V., "Flow Quality Measurements in the NASA Ames Upgraded 11-By 11-Foot Transonic Wind Tunnel," Paper \# 2000-2681, $21^{\text {st }}$ AIAA Advanced Measurement Technology and Ground Testing Conference, Denver, CO, June 19-22, 2000. 